These two images arise from a certain familiarity with musical performance as well as with leadership issues in a day hospital or an admission ward. They cannot of course be taken too far. Indeed several other ideas might also stimulate debate. An image of the doctor as 'manager', or manager as 'consultant', might also be usefully explored.

There is, however, a need for the College, and government, to acknowledge good practice and recognise that a consultant-based team is in most instances also optimally consultant-led. Most other mental health professionals do not seek, nor do they wish for, such responsibility - nor are they paid for it. This 'parental' leadership, embedded in NHS tradition, is unlikely to be radically changed by a cultural shift; it should however be earned and sustained through specific continuing education, and in particular by training within a clinical setting.

It is hoped that the President's working party will continue to address these issues and that its report will be heeded by managers and managed.

John L. Cox, Dean, Royal College of Psychiatrists

\title{
Sexual harassment of staff by patients in mental health units
}

\author{
Maria B. Tomé de la Granja
}

The Health and Safety Executive (1992) defines violence against staff as "any incident in which an employee is threatened or assaulted by a member of the public in circumstances arising out of the course of his or her employment". Verbal abuse and threats are, as the Health and Safety Executive notes, the most common types of incidents, and staff have the common-law right to be protected from such incidents in the course of their work. While the literature on physical violence against mental health professionals is quite large and expanding (see, for example, Health and Safety Commission, 1987; Shepherd, 1994; Wykes, 1994), comparatively little emphasis has been placed on verbal assaults, although these may be extremely distressing.

A common problem in our unit (a rehabilitation unit associated with a community sectorised service in an inner city) is sexually provocative comments to female and, rarely, male staff by patients. An informal poll of colleagues in all disciplines indicates that our unit is far from unique in this. A frequent feeling in the victim of such comments, which amount to sexual harassment, is of frustration because one does not know how to deal with it, and particularly because one is unsure that the matter will be taken seriously. We are implementing a unit policy on sexual harassment by patients. The policy is given below, as 'Eight Commandments'. It seeks to complement and not replace existing policies on sexual harassment at work.

(1) We regard it as fundamental that members of staff should be able to perform their duties and patients their treatment and rehabilitation without sexual harassment and that the unit will not tolerate such behaviour. In other words, sexual harassment is not to be regarded merely as an occupational hazard. It is important that this message is made clear to all, including patients.

(2) Sexual harassment occurs when a member of staff suffers annoyance and/ or impedance in his or her work due to words or actions that make it plain that the member of staff is considered not as 
an individual worker but in a genderspecific manner irrelevant to his or her capacities for the hard work in hand.

(3) The following sections apply to nonviolent instances of sexual harassment. These are usually verbal in nature and may take, for example, the form of sexually inappropriate comments about the staff member's appearance. More severe examples include sexually inappropriate touching.

(4) Each time that sexual harassment occurs, it should be reported. If the victim is a patient, then the incident should be reported to the patient's keyworker. A member of staff should report to their line manager, or, in the case of medical staff, to their consultant or deputy in the first instance.

(5) In each case, the alleged perpetrator should be informed of the allegation of sexual harassment and invited to give his or her side of the matter. This should take place when practicable after the event.

(6) It must be emphasised to the perpetrator, in private or public, depending on the nature of the offence, that sexual harassment is never acceptable, and the immediate goal should be to educate the perpetrator about why this is so. It may be, for example, that specific training in social skills is required.
(7) Violent sexual harassment is construed not as simply uncomfortable or annoying, but in the same light as any other violent attack. The position must be reviewed and a policy of involvement of the police should be considered.

(8) Incidents of sexual harassment must be monitored and the action taken is to be recorded. The victim should be allowed to express him or herself satisfied by any such action taken.

I present this policy as a nucleus around which others may wish to build. However, I also hope that more open discussion may be stimulated on a topic that has been a continual, but almost hidden, aspect of the working lives of many in the mental health professions.

\section{References}

Henlth and Safety Commission, Henlth AdVisory Service (1987) Violence to Staff in the Health Services. ISBN 0118839179 . HMSO.

HEALTH AND SAFETY EXEECUTIVE (1992) Violence to Staff.

SHEPHERD, J. (1994) Violence in Health Care: a practical guide to coping with violence and carting for victims. Oxford Untversity Press.

WYkes. T. (1994) Violence and Health Care Professionals. Chapman and Hall.

Maria B. Tomé de la Granja, Registrar, Maudsley Hospital, Denmark Hill, London SE5 8AZ 